\title{
MOOCS - A FORCE TO BE RECKONED WITH OR A TEMPORARY PHENOMENON
}

\author{
Gerhard Koenig \\ Geodesy and Geoinformation Science, Technical University Berlin, Berlin, Germany - gerhard.koenig@tu-berlin.de
}

Commission VI, WG VI/2

KEY WORDS: Education, Training, Teaching, Multimedia, Internet, Web based, Open Systems, Resources

\begin{abstract}
:
The digital revolution has dramatically changed our everyday life. Using the Internet has evolved into a key technology that became an indispensable information source. The expansion of Internet usage beyond mere information storage to a learning and communication tool sets new standards for the development of educational concepts. Digital textbooks, multimedia tutorials, elearning offers using learning management systems and massive open online courses (MOOCs) demonstrate the development phases of new strategies for knowledge transfer. Initially starting in the USA MOOC platforms like Udacity, Coursera or edX had gained an enormous media attention caused by the huge number of participants. Initially this new teaching method was welcomed euphorically; the didactic preparation of courses is however viewed with scepticism, particularly in Europe.
\end{abstract}

This paper will review the status of MOOCs, with a particular emphasis on Photogrammetry, Remote Sensing, and Geomatics. A selection of these 'Geo-MOOCs' will be presented. The consideration of these free online learning resources will include a commentary on quality and perceived effectiveness. Finally it will be outlined if MOOCs are reasonable and promising in our fields.

\section{INTRODUCTION}

Modern educational concepts need training opportunities that are able to prepare people for a professional working life. Employers assume that employees have a high degree of personal responsibility focusing on technical knowledge as well as on interpersonal communication skills. To foster competency development high expectations are directed to IT-supported learning offers and their potential for implementing innovative educational approaches.

Distance education has a long tradition, especially the spread of Internet has emerged constantly evolving learning technologies. With the beginning of the 21th century IT-based distance education courses enjoyed great popularity that lead to rapidly increasing participation. Access to education is now globalised and independent from traditional geographical limitations and barriers. Online training has opened new opportunities for acquiring education and skills that allow students to participate in courses at own flexible pace without giving up employment or family commitments.

Great public interest aroused end of 2011 when Sebastian Thrun, Professor of Computer Science at Stanford University, offered an open course on Artificial Intelligence, which was attended by 160.000 people. This new type of educational offer - called massive open online courses (MOOCs) - demonstrated that free access to subject matter could open education to interested parties irrespective of their educational backgrounds and broaden access to post-secondary education for members of social classes that are underrepresented in higher education. Therefore Thrun stated initially MOOCs as contribution to democratising education.

In the meantime a variety of providers flooded the market and offered thousands of MOOCs of varying quality. Educational institutions, especially the universities, take MOOCs as an opportunity to question the traditional teaching methods and think about their impact on its educational mission. Companies check whether MOOCs are suitable for training their employees.

\section{MASSIVE OPEN ONLINE COURSES}

The amount of MOOCs is increasing continuously. Dhawal Shah has compiled data on the state of the MOOC market, based on a statistic including more than 2400 courses hosted by 400 providers, supervising 16-18 million students (figure 1).

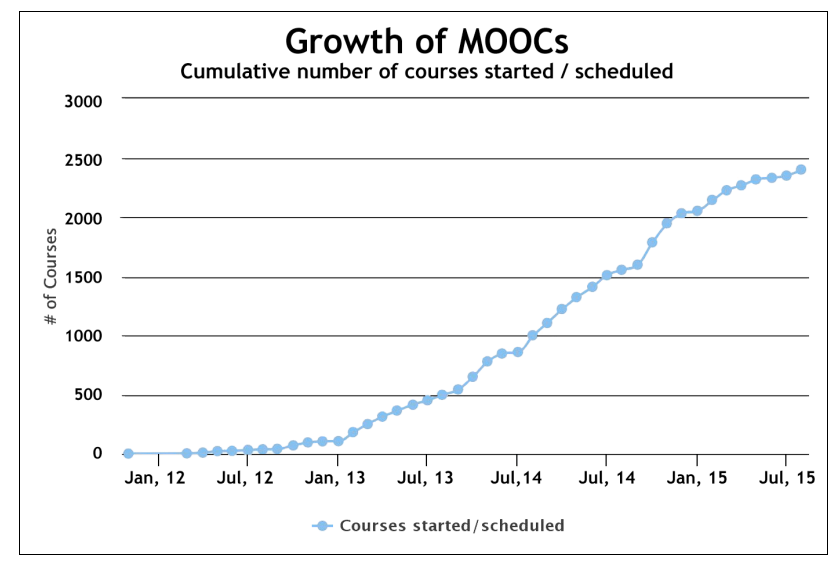

Figure 1. Growth of MOOCs (Shah, 2014)

MOOCs are characterised by a variety of features: they allow an unlimited number of people to attend; participants' restrictions and entry requirements do not exist. Courses are open to everyone, are offered free of charge, and carried out completely online. Two general types of MOOCs can be distinguished dependent on their didactical background, but also several variants emerged. 


\section{1 cMOOC}

Based on the connectivist pedagogy, introduced by the Canadian learning theorist George Siemens, a variety of cMOOCs were organised and tested. "Connectivism is the thesis that knowledge is distributed across a network of connections, and therefore that learning consists of the ability to construct and traverse those networks" (Downes 2012). In this sense knowledge is distributed across a large network of individual sites and services that follows the principles of autonomy, diversity, openness and interactivity. Accordingly, cMOOCs require participants who play an active part in the course by gathering existing content and information and submitting their own opinions - its learning by sharing. For this purpose different social media tools such as blogs, Twitter, or online editors are used. Course outcomes are often unique products, such as blog posts, images, diagrams, or videos generated by participants (Hollands et al. 2014).

Best-known is the online course Connectivism and Connective Knowledge offered by Siemens and Stephen Downes in January 2011 applying this didactic approach. The course content was available through RSS feeds, and free to anyone who wished to participate. Over 2000 people enrolled worldwide (see http://cck11.mooc.ca/).

\section{$2.2 \times$ MOOC}

The broad majority form so called xMOOCs that are based on traditional concepts, where - in contrast to cMOOCs participants are not responsible for providing the learning material. Course developers produce videos for a specific topic, and arrange them together with small tests or quizzes between the course sections to form a learning unit. Multiple-choice tests are standard practice. The course is conducted according to a fixed class schedule every week, in general for 6-8 weeks in total. To master the immensely high correction effort computercontrolled evaluation is usual. Another method is to request participants to give feedback to exercises submitted by their fellow students (peer reviewing). In addition, participants could organise activities in social networks or form of group meetings on site. A moderator giving additional support and advice could be engaged to manage forums in most cases. At the end of a MOOC an exam is mandatory for gaining a certificate, but in general it implies neither the award of credit points nor the conferment of a university qualification. User identity is not controlled in most cases, but in some courses an optional "Signature Track" is introduced. After successful participation a "Verified Certificate" is issued. This business model is liable for costs: users have to pay a fee that varies around US\$ 50 .

\subsection{Blended MOOC}

A xMOOC variant is the Blended MOOC that complements classroom sessions and is embedded in an existing degree programme. This allows enrolled students to collect credit points for their studies.

\subsection{MOOC providers - the big players}

Organising courses for the huge amount of users has to comply with exacting technical requirements (hardware / software) and personal power. To maintain this service organisations and companies are responsible for smooth and secured operation. This chapter will introduce the biggest providers located in US and Europe.

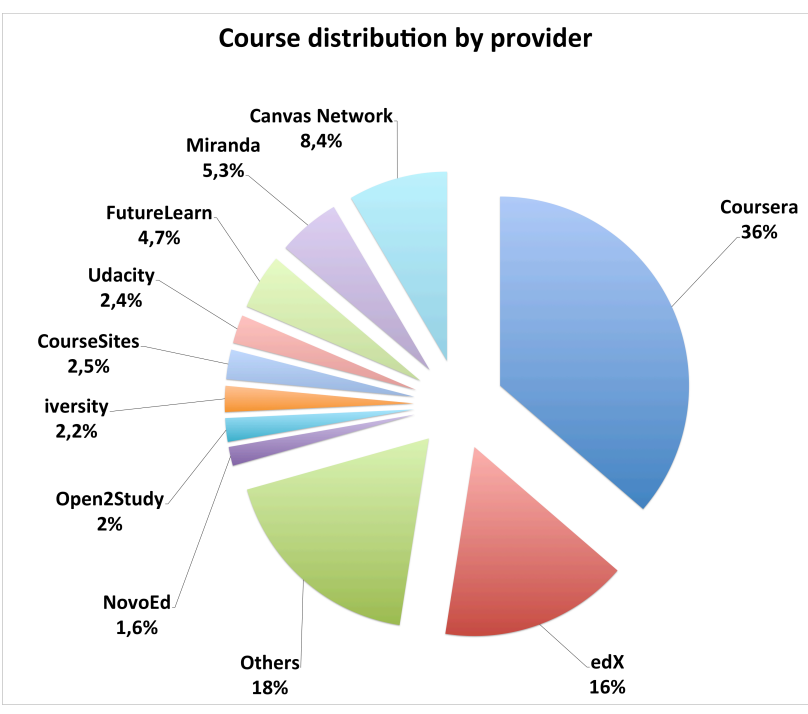

Figure 2. Participants distribution by provider (Shah, 2014)

\subsubsection{Udacity}

Encoraged by the high number of participants in the course Introduction to Artificial Intelligence Sebastian Thrun and his partner founded Udacity in early 2012. Udacity is funded by venture capital firms and has about 2.8 million students from 119 countries (2014).

Up to now the classes' focus is put on computer science, programming, and math topics. In contrast to MOOCs offered by the competitors, a participant can attend courses whenever he likes. This has the advantage that he can start immediately and work on his own pace, but on the other hand there are fewer students active in a forum that can give support if necessary. Teaching material is developed by Udacity with support of visiting teachers or cooperate partners, giving courses a homogeneous structure. In November 2013, Thrun practices self-criticism and stated that the courses are a "lousy product" (Chafkin, 2013). As a consequence, he announced that Udacity will focus on vocational courses that offer formal degrees, which are subject to charges. Udacity now cooperates with companies to deliver customised services for their needs. Socalled Nanodegree courses are available for US\$ 200 per month. Udacity is also involved in the first accredited online master's degree program of the Georgia Institute of Technology in cooperation with AT\&T: the total cost of the a complete degree amounts to US\$ 7,000.

\subsubsection{Coursera}

Another MOOC-pioneer is Coursera The company was founded in April 2012 by computer science professors Andrew $\mathrm{Ng}$ and Daphne Koller of Stanford University. Coursera is the largest provider in terms of courses. As of March 26, 2015, Coursera had 12 million subscribers enrolled from 190 countries. It offers more than 1000 MOOCs from 117 partner universities worldwide (April 2015). The company has been able to raise medium to high double-digit millions US dollar in venture capital.

Coursera tries to stand out among other MOOC competitors emphasising high quality standards. Exclusively elite universities, world-famous companies and renowned scientists are allowed to offer teaching materials. By providing a range of courses for non-technical studies and jobs, Coursera has managed to offer a diversified portfolio. The courses are 
acessible during a specific time period only and have a fixed end date. Assignments and exams may not be submitted after their due dates. Students have to take care on strict deadlines for finishing exercises if they are interested in getting a certificate. Participants can therefore work at their own time but not on their own pace. Courses can be studied for free; if an individual, graded certificate is desired, online authentication is necessary (Signature track) at a charge of currently US\$ 49.

Also keeping an eye on employers Coursera has set up the Specialisation Certificate granted to participants who take part in a series of courses. Students who passed the exams successfully have to pay between US\$ 250 to 500 .

\subsection{3 edX}

edX is a not-for-profit enterprise composed of 30 leading global institutions, the xConsortium. It's a learning platform, initiated by the Massachusetts Institute of Technology (MIT) and Harvard University in May 2012. edX offers online universitylevel courses in a wide range of disciplines; STEM subjects predominate yet. As of May 15, 2015 edX has 2,8 million registrants in 195 countries and offers more than 500 courses. All edX courses can be audited for free, as well as many of edX's past courses that are archived.

Similar to the competitors offers three certificate variants:

- Honor Code Certificate that doesn't verify participants' identity (free of charge),

- Verified Certificate of Achievement (cost varies depending on the courses US\$25-100), only available for few classes, students have be identified by photo and ID, and

- XSeries Certificates for completion of a bundled set of two to seven verified courses in a single subject (cost varies depending on the courses - up to US\$ 500 per series)

The edX platform is available as open-source software for other institutions, which intend to offer MOOCs.

\subsubsection{FutureLearn (United Kingdom)}

The private company FutureLearn is located in UK already attracted 1.6 million people. As of March 2015 FutureLearn hosts 57 university partners. Moreover, the British Museum, the British Council, the British Library and the National Film and Television School also participate. It's free to join and study any course. On demand students can obtain a

- Statement of Participation if 50\% of course content was finished successfully including tests and quizzes ( $£ 29$ per statement) or a

- Statement of Attainment. These are university-branded, printed certificates that provide proof of learning on the course topic(s).

FutureLearn exams are computer-based exams. Conducting the final exam is only available at physical test centres under invigilated conditions. Students' identity will be verified at the test centre. Examination fee is between $£ 119$ or $£ 149$.

\subsection{5 iversity (Germany)}

The MOOC platform iversity.org operates since October 2013. iversity is cooperating with 41 universities and offered 63 courses so far. 600,000 users are registered (February 2015). Some of the courses were selected in the MOOC Production Fellowship competition hold by iversity and the Association for the Promotion of Science and Humanities in Germany. Students can choose between different study paths for obtaining different certificates.

- Audit tracks are free of charge, in contrast to the

- Certificate track that includes additional services, and confirms successful participation, and

- ECTS track, which is of special interest for students:

The European Credit Transfer and Accumulation System (ECTS) is a standard that ensures that the study attainments of students in higher education are comparable. Universities that offer courses on iversity.org, can assign ECTS points. ECTS points are creditable as part of university studies on-campus. At the end of a course a written examination or a final project has to be passed. Exams can take place on-site or are conducted online under remote control. Iversity charges for a two semseter course in business economics 269 Euro.

\section{MOOCS EXAMPLES}

The range of courses is continuously increasing. Getting an overview on courses indeed is difficult. Accessing MOOC indexes, such as Class Central, MOOC List, or the European MOOCs Scoreboard, can facilitate searching MOOCs. Figure 3 gives an overview about which subjects are covered by MOOCs. Courses that are of interest in our fields are mainly related to Computer Science topics. GIS related courses are growing, but Geodesy, Remote Sensing, Photogrammetry and Cartography seem not to be attractive for the MOOC mass market. In the following paragraphs a selection of Geo-MOOCs is introduced.

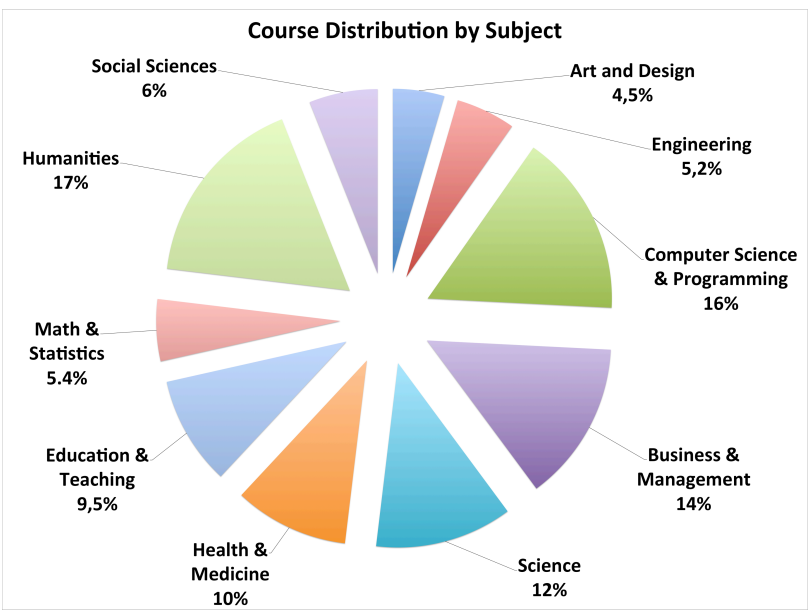

Figure 3. Course distribution by subject (Shah, 2014)

\subsection{Computer Science: CS50 2015 (edX)}

At Harvard University David J. Malan's course CS50 2015 related to Computer Science and the art of programming is a well-established course that is annually repeated. The course starts with basics explaining most important computer terms. Programming in $\mathrm{C}$ forms the next unit taking 6 weeks. The course continues with 3-weeks web-related topics (TCP/IP, HTTP, HTML, VSS, PHP, MVC, SQL, JavaScript, and Ajax), and finally focuses on security issues. Malan is a very lively speaker who can present his expert knowledge convincingly. 




Figure 4. David Malan - CS50

https://courses.edx.org/courses/HarvardX/CS50x3/2015/

Nine problem sets are assigned during the semester. To receive a certificate, students must submit the exercise in time. A final project work to verify acquired programming skills completes the course - students can determine the subject themselves, which must be approved by the supervisors.

Participating the course is free of charge, including a Honour Code Certificate. The expenses for obtaining a Verified Certificate amount to US\$ 90. Enrolled students at Harvard University can get a CS50 Certificate for US\$ 1000. In all three cases students' problem sets are auto-graded and evaluated by a CS50's server. If personalised feedback is required by teaching fellows, students' have to attend the classes within the lecture period and hand in exercises weekly. Students who earn satisfactory scores will be assigned a transferable course credit (US\$ 2000).

3.2 Duke University: Image and video processing: From Mars to Hollywood with a stop at the hospital (Coursera)

This course instructed by Guillermo Sapiro took place three times in 2013, 2014 and 2015. The course hosted by Coursera lasts 9 weeks covering the fundamentals (image and video processing, compression, spatial processing, image restoration, image segmentation). The presentation of this part is based on the book Digital Image Processing by Gonzalez and Woods. Further topics focus on geometric partial differential equations for image enhancement and object detection, image and video impainting, sparse modelling and compressed sensing. Finally the course ends with an example for medical image analysis.

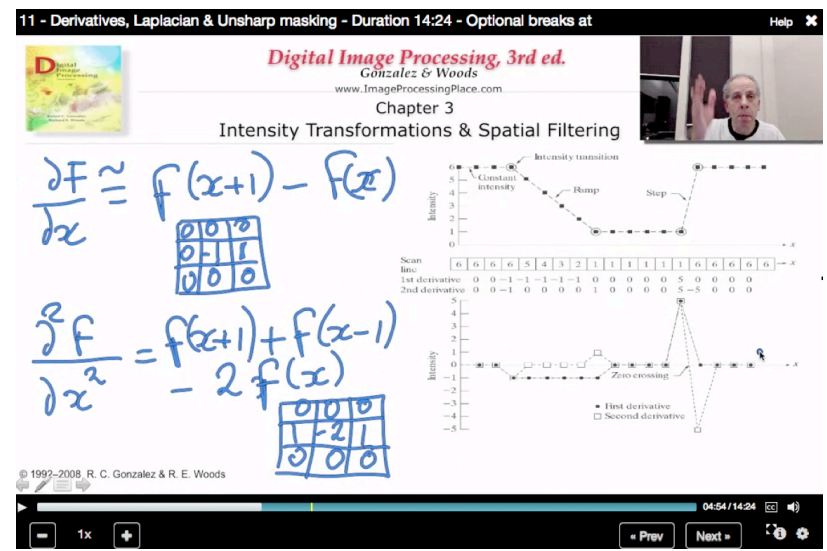

Figure 5. Image and Video Processing https://www.coursera.org/course/images

The course is split in lecture videos of less than 15 minutes length and enriched with weekly quizzes (mostly multiple choice tests, also requesting results of numerical calculations, and a few short answer questions). Frequently assigned programming exercises are optional and could be solved using MATLAB, which is provided by MathWorks during the course period for free. Good math and programming skills are beneficial.

3.3 Northwestern University: Fundamentals of Digital Image and Video Processing (Coursera):

A similar course to the previous one is held by Aggelos K. Katsaggelos. First started on March 2014 it is repeated this year. The 12 weeks course provides a mathematical framework to describe and analyse images and videos as two- and threedimensional signals in the spatial, spatio-temporal, and frequency domains.

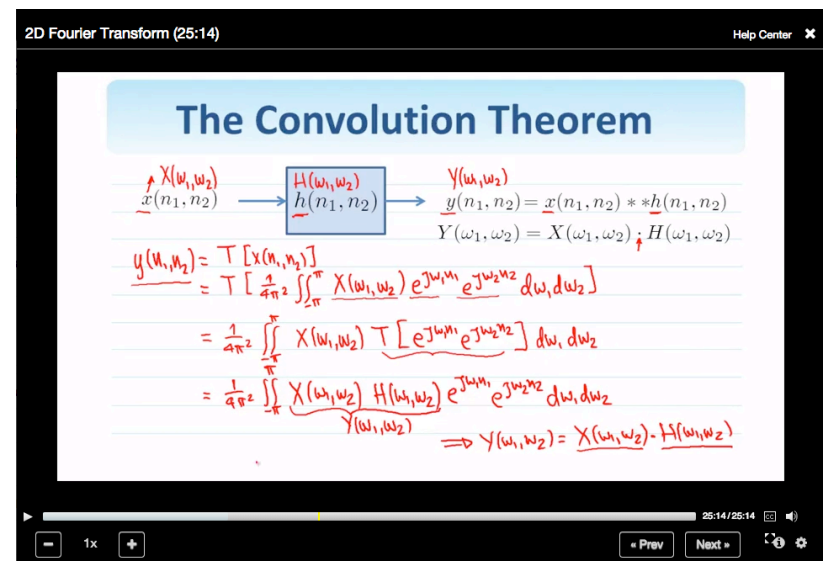

Figure 6. Fundamentals of Digital Image and Video Processing https://www.coursera.org/course/digital

The class consists of video lectures split into short chunks no longer than 30 minutes. Some of these may contain integrated quizzes (multiple-choice questions, fill-in-the-blank, true-orfalse problems), as well as programming assignments. To complete the programming tasks students have access to MATLAB Online. To obtain the Statement of Accomplishment or Signature Track Verified Certificate, participants will need to score at least 80 (of 100). The presentation style is reminiscent of university lectures (and is similar to Guillermo Sapiro presentation). Annotations given during the lectures, such as deriving formulas or adding sketches are helpful for a better understanding (see figures 5 and 6). Good math and programming skills are advantageous here too.

3.4 Penn State University: Maps and the Geospatial Revolution (Coursera)

First introduced in July 2013 the course was repeated in 2014 and 2015, performed by Anthony Robinson and his team. Course content consisted of five lessons focussing on the massive changes in geospatial and mapping technology. It highlighted how spatial data is created, and how technologies such as spatial analysis are used for contributing to solve geographic problems that take spatial relationships into account. One main focus was put to cartographic techniques and design.

The lessons featured short video lectures of 5 to 11 minutes length, written content, explanatory graphics, hands-on mapping activities, and discussion assignments. Students were evaluated through weekly quizzes (weighted 40\%), discussion participation $(10 \%)$, and video and mapping assignments. The 
final examination consists of 50 questions to be solved within 120 minutes (30\%) and a mapping assignment that makes use of Coursera's Peer Assessment tool (20\%). Based on a scoring criteria fixed by the course team each student had to review five other classmates' work.

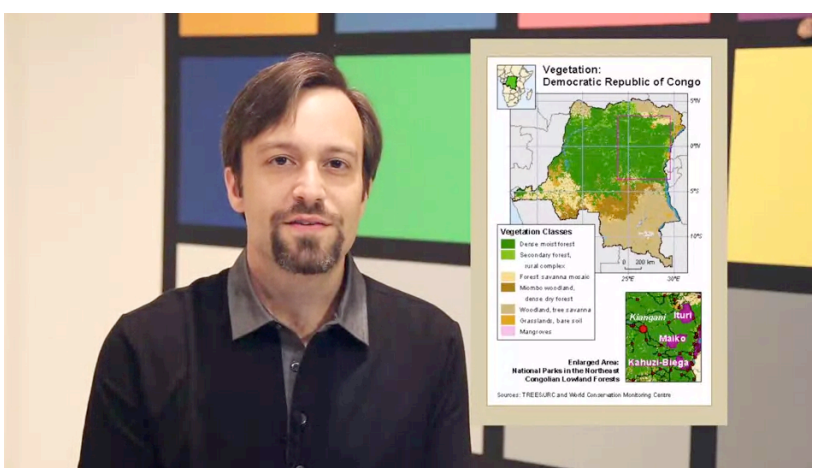

Figure 7. Maps and the Geospatial Revolution https://www.coursera.org/course/maps

At the end of the class, a Statement of Accomplishment was issued to those students who passed the course. Support was given by ESRI making ArcGIS Online available to the participants.

\subsection{ESRI: Going Places with Spatial Analysis (Udemy)}

High quality web-based learning material is available from ESRI since 1997. ArcGIS user can find on ESRI's webpage training.esri.com dozens self-paced or instructor-led training courses combined with hands-on-exercises, rich instructional resources, and optional exams with personalized completion certificates. Now the company decided to offer its first MOOC on spatial data analysis. The MOOC launched in September 2014, was repeated in March 2015 and will take place in September 2015 again. The course lasts six weeks and requires two to three hours of study per week. It consists of short video lectures, quizzes, case studies, and offered the opportunity for discussions and questionnaires using GeoNet, ESRI's platform for sharing, chatting, and collaborating information.

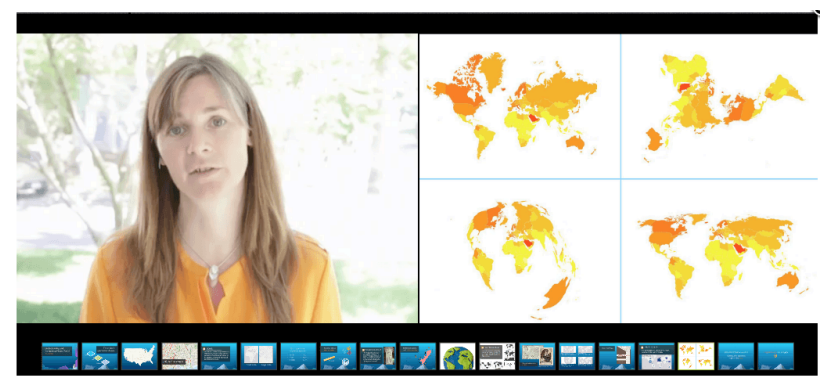

Figure 8. ESRI - Going Places with Spatial Analysis http://www.esri.com/training/main

Students learn to apply spatial analysis to make informed decisions in a variety of contexts, from land-use assessment to crime analysis to pollution modelling and environmental justice, and more. Participants get free access to the full analytical capabilities of ArcGIS Online for handling the exercises.
3.6 University of Minnesota: From GPS and Google Maps to Spatial Computing (Udacity)

A further GIS-related course was held Brent Hecht and Shashi Shekhar from the University of Minnesota in April 2015. This course introduced fundamental concepts underlying spatial computing services, systems, and sciences. Students were able to know about spatial data structures, SQL, spatial data mining, and gain an overview on current tools and techniques such as global positioning systems (GPS), Google Maps, location-based services and geographic information systems. Also background information is given about collecting, distributing, and using Volunteered Geographic Information. This course is designed to support three different types of students and educational goals:

- Curiosity Track: for students who intend to get a brief overview and want to focus on few topics only - no certificate is granted

- Concepts Track: participants who want to apply spatial computing concepts only and have completed the course successfully will receive a Statement of Accomplishment.

- Technical Track: Students interested in understanding the mathematical theory and intend to strengthen their programming skills take this track. They will be graded with a Distinguished Statement of Accomplishment.

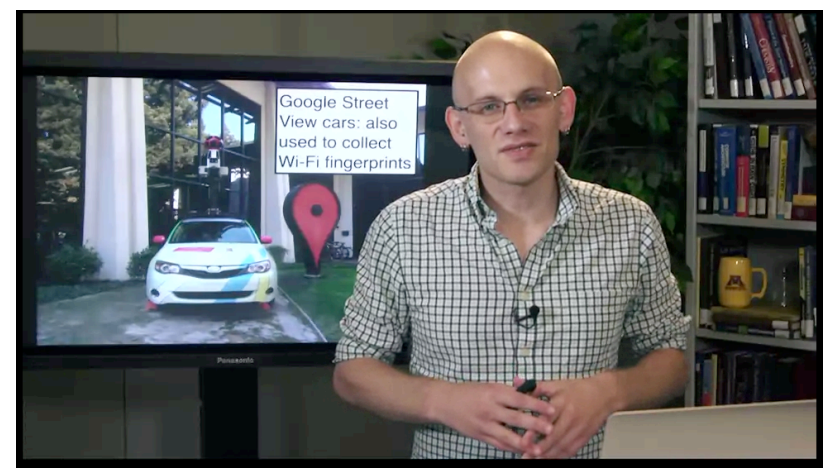

Figure 9. B. Hecht - Spatial Computing

https://www.coursera.org/course/spatialcomputing

3.7 Elmhurst College: Skills for the Digital Earth (Desire2Learn (D2L) OpenCourses)

As an outsider, the Elmhust College goes into the race, offering the MOOC Skills for the Digital Earth. This 4 weeks course was held the second time, now taught by Judith Bock, Program Director, Department of Geography and Geosciences at Elmhurst. Course syllabus consists of seven modules, starting with an introduction to fundamental geography, to basic computing knowledge, and reasoning skills. Furthermore, students get acquainted with tools and techniques for gathering, storing, transforming, and manipulating spatial data, and ate taught in the field cartography, remote sensing, location-based services, and business. Certificates are granted upon successful completion, which can be used as waiver to further GIS related courses at Elmhurst College.

\section{MOOCS - PROS AND CONS}

The continuously increasing amount of MOOCs indicates that MOOCs as new learning technology are accepted and out of the question. But taking a closer look leads to some critical remarks. 


\subsection{Prevalence rate}

At Harvard University, a comprehensive statistics to their own MOOCs was published. This statistics is representative for nearly all providers. In total 2,710,444 people from 195 countries have registered for one of their courses. Details are visualised in an interactive map illustrates the (estimated) enrolment numbers from each country for all HarvardX offerings (Nesterko et al, 2014).

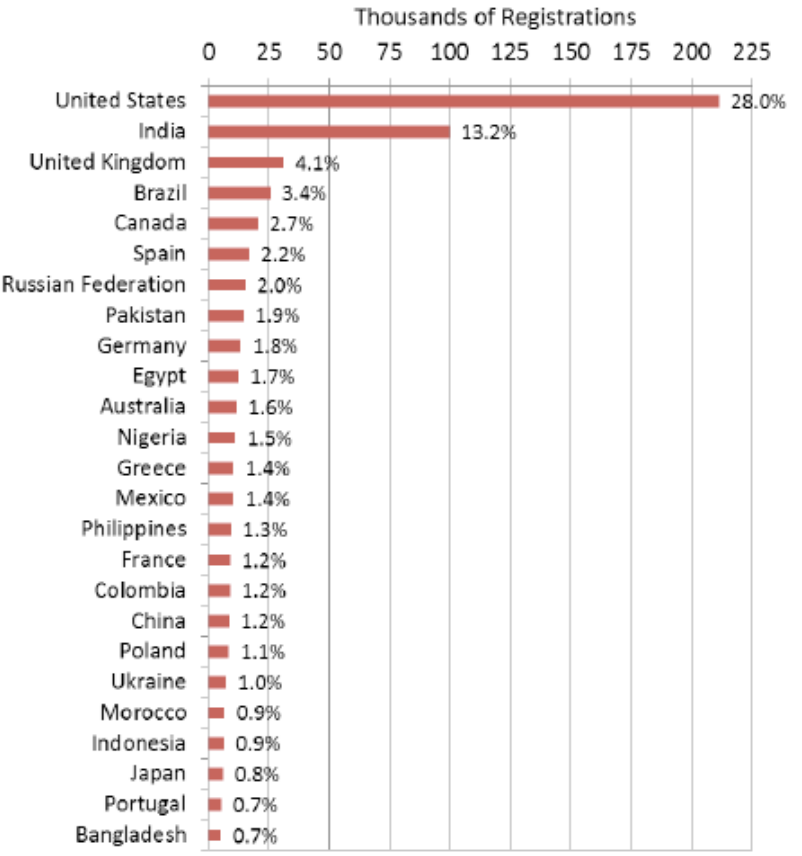

Figure 10. The top 25 countries, by numbers of registrants, for all HarvardX and MITx registrants. (Ho et all, 2014)

Figure 10 ranks the top 25 countries by the numbers of registrants (Ho, 2014). It's not surprising that most of the participants come from the USA. This fact is directly linked to the structures of the American higher education system because students emerge immensely high cost to achieve an academic degree. This pressure does not exist in most European countries, the interest in participating open online courses is much lower. Developing countries and emerging nations, however, benefit from the opportunities that arise from MOOCs and use these courses much more frequently.

\subsection{MOOC user profile}

MOOCs contribute to the democratisation of education - this was one substantial argument at the beginning of the MOOC wave. But statistics point out that the offer doesn't expand access to higher education to those who do not already have the means to obtain it. A study of students participating in Penn's Coursera courses proved this apprehension (Christensen et al., 2013). The authors of the study received 34,779 completed responses from individuals having watched at least one course lecture. As listed in table 1 the majority of participants worldwide is employed full-time or self-employed. A main difference between Brazil, Russia, India, China, and South Africa (BRICS) and developing countries in contrast to US and OECD nations concerns the age: nearly two thirds of students are under age of 30 . The survey also revealed that across all geographic regions, MOOC students have very high levels of educational attainment: $83.0 \%$ of students a post-secondary degree ( 2 or 4 years), $79.4 \%$ of students have a Bachelor's degree or higher and $44.2 \%$ report education beyond a Bachelor's degree. These results are confirmed by the survey at Harvard (Ho et al, 2014).

\begin{tabular}{|c|c|c|c|c|c|c|}
\hline & & $\begin{array}{c}\text { Total } \\
34.779\end{array}$ & $\begin{array}{c}\text { US } \\
11.933\end{array}$ & $\begin{array}{c}\text { OECD } \\
10.784\end{array}$ & $\begin{array}{l}\text { BRICS } \\
5.151\end{array}$ & $\begin{array}{c}\text { Developing } \\
6.911\end{array}$ \\
\hline \multirow{2}{*}{ Gender } & Male & $56,9 \%$ & $41,1 \%$ & $58,4 \%$ & $67,9 \%$ & $61,4 \%$ \\
\hline & Female & $41,3 \%$ & $49,4 \%$ & $39,9 \%$ & $31,1 \%$ & $37,3 \%$ \\
\hline \multirow{2}{*}{ Age } & Under 30 & $41,1 \%$ & $23,3 \%$ & $37,1 \%$ & $63,4 \%$ & $58,8 \%$ \\
\hline & Over 30 & $58,9 \%$ & $76,5 \%$ & $62,9 \%$ & $36,6 \%$ & $41,2 \%$ \\
\hline \multirow{6}{*}{ Employment } & Student & $17,4 \%$ & $9,8 \%$ & $16,4 \%$ & $28,2 \%$ & $23,9 \%$ \\
\hline & Part-time & $6,9 \%$ & $7,2 \%$ & $7,5 \%$ & $5,3 \%$ & $6,6 \%$ \\
\hline & Full-time & $50,0 \%$ & $51,1 \%$ & $48,9 \%$ & $49,4 \%$ & $50,0 \%$ \\
\hline & Self-employed & $12,4 \%$ & $11,2 \%$ & $14,2 \%$ & $11,8 \%$ & $12,0 \%$ \\
\hline & Unemployed & $6,6 \%$ & $6,6 \%$ & $8,2 \%$ & $4,1 \%$ & $5,8 \%$ \\
\hline & Retired & $6,8 \%$ & $14,0 \%$ & $48,0 \%$ & $12,0 \%$ & $17,0 \%$ \\
\hline
\end{tabular}

Table 1. Penn State University - Students' statistic

\subsection{The dropout rate}

Only a small portion of students who had signed up for a course makes it to the end. This started a debate on dropout rates, which retains to the present day. The survey based on participant data from Coursera, Udacity and edX confirmed that the completion rate was in between $0.9 \%$ to $36.1 \%$. An average of $6.5 \%$ fulfilled the criteria for obtaining a certificate of attendance (Jordan 2014). This could be caused by participants' motives, which are very heterogeneous. Only few students start a course with the aim to obtain a certificate of attendance (active students). Some participants view a course as content to consume and expect to be taught (passive students), others become partially or fully active participants for a selected topic (drop-ins), some sign in (lurkers), but never start the course, or just observe or sample a few items at the most (Hill, 2013). Nevertheless, low course completion rates are evidence that MOOCs are not suitable for everyone.

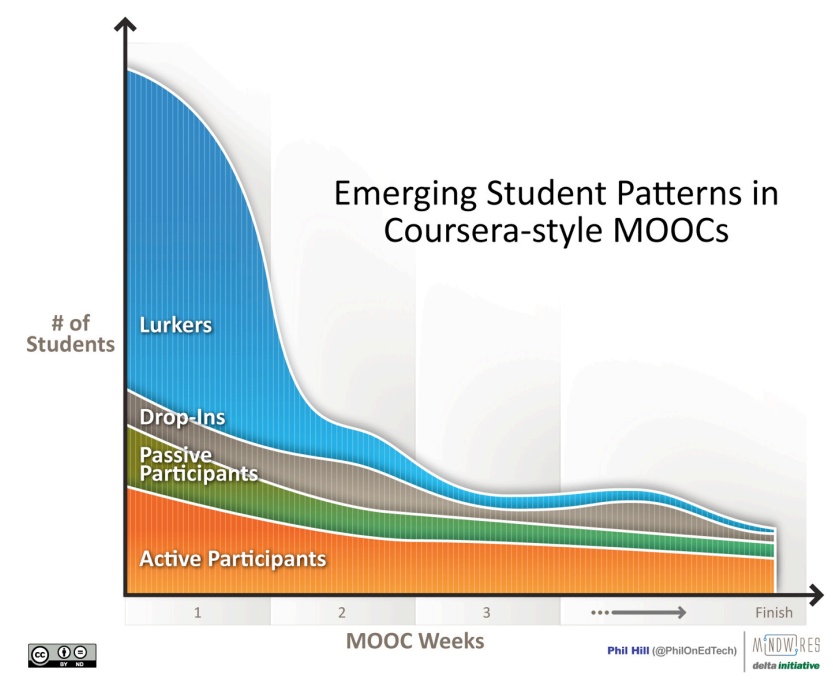

Figure 11. Users' learning motivation (Hill, 2013)

\subsection{Didactics}

Rolf Schulmeister, German university professor specialised on the didactics and mass media development, is a critical observer of new learning technologies. He has a sceptical look at the MOOCs didactics and states that the connection of short video learning units with stereotypical assignments and tests - mostly in multiple-choice format - and simple, automated forms of feedback is a (outdated) combination of behaviorism and instructional methods, which addresses extrinsically motivated 
learners only. The integration of discussion forums cannot hide the fact that communicative and interactive aspects are missed out. "XMOOCs are suitable for imparting knowledge; they are less suitable for facilitating understanding or training of problem awareness. Thus, it would be sensible to evaluate the success of xMOOCs with respect to imparting knowledge. Feedback refers to multiple-choice answers and is mostly purely formal, not related to content" (Schulmeister, 2014). The lack of communication, the lack of support and supervision by teachers or tutors, the missing individual feedback on learning activities are criticisms that are mentioned in the discussion of the didactics quality of xMOOCs repeatedly (Robes, 2015). And also Chafkin states: "Learning, after all, is about more than some concrete set of vocational skills. It is about thinking critically and asking questions, about finding ways to see the world from different points of view rather than one's own. These ... are not skills easily acquired by YouTube video" (Chafkin 2013). It is obvious that a single professor or expert is unable to communicate with thousands of students. Therefore most MOOC providers now offer individual support for a fee.

\section{CONCLUSION AND OUTLOOK}

When the first MOOC providers began developing and implementing their online courses they focused on academic education. This was caused by the exorbitant tuition fees students have to pay each year. But studies suggest that MOOCs are only marginally of interest to undergraduate students - at least under the current conditions. This could change, however, if solutions for accepting credits are found and above all the MOOC courses offered are compatible with existing curricula. Currently, however, first cooperation steps of providers and universities are visible, but not exempt from charges. There is still another aspect: students are put off by the high number of participants and prefer more face-to-face interaction experiences with their instructors "It appears, at least for the time being, that MOOCs are not a threat to traditional higher institutions or programs of study but instead are emerging as an alternative educational platform that can supplement and expand the market for higher education rather than supplant the college/university experience" (Dahlstrom et al., 2013). Most experts share this opinion and many of them see the future of MOOCs embedded in blended learning or flipped classroom concepts.

Meanwhile the leading MOOC providers recognized that university students are not their primary audience, but rather people in employments who intend to update their skills to remain competitive in their job. Providers therefore changed their business model and offer courses available for fees. "In MOOCs that are funded by venture capital (Coursera, Udacity a.o.) decisions are made by the investors, for whom returns on investments are the key concern, not people's hopes and dreams. And even in MOOCs such as Harvard and MIT's edX, funded by donations, influence may be granted as a token of good will but not as a right. ... on a widely shared understanding of democratic, MOOCs cannot be said to democratise education" (Sloep, 2013).

But what is the impact of MOOCs on our fields? So far they have little influence. Geo-MOOCs are scarce, only few examples related to our special subjects. However, the examples listed here show that university students certainly can benefit from MOOCs. Unlike many courses the tasks consist not only of simple or even mindless tests. Students must write programs, draw maps or can gain experience in operating software tools. In some cases (CS50, Geospatial revolution), participants can even decide on the topics they want to work in the final exercise. Most importantly, it is to find courses that motivate the participants. This includes a good structure, a very good organization, excellent videos, and a lively forum. However, much more depends on the personality of the presenter and his/her enthusiasm or passion for the subject - but that's similar to $\mathrm{f} 2 \mathrm{f}$ courses.

\section{REFERENCES}

Chafkin, M., 2013. Udacity's Sebastian Thrun, Godfather of Free Online Education, Changes Course. In: Fast Company. URL: http://www.fastcompany.com/3021473/udacity-sebastianthrun-uphill-climb

Christensen, G. and Steinmetz, A. and Alcorn, B. and Bennett, A. and Woods, D. and Emanuel, E. J., 2012. The MOOC Phenomenon: Who Takes Massive Open Online Courses and Why?. URL: http://papers.ssrn.com/sol3/papers.cfm? abstract_ id $=2350964$

Dahlstrom, E.; Walker, J.D.; Dziuban, Ch., 2013. ECAR Study on Undergraduate Students and Information Technology. Louisville, CO. Educause Center, 2013. URL: https:// net.educause.edu/ir/library/pdf/ERS1302/ERS1302.pdf.

Downes, S., 2012. Connecitvism and Connective Knowledge Essay on meaning and learning networks. 616 p. URL: http://www.downes.ca/files/books/Connective_Knowledge19May2012.pdf

Hill, P. 2013: Emerging Student Patterns in MOOCs: A (Revised) Graphical View, e-Literate. URL: http://mfeldstein. com/emerging_student_patterns_in_moocs_graphical_view/

Ho, A. D., Reich, J., Nesterko, S., Seaton, D. T., Mullaney, T., Waldo, J., \& Chuang, I., 2014. HarvardX and MITx: The first year of open online courses (HarvardX and MITx Working Paper No. 1). URL: http://papers.ssrn.com/sol3/papers.cfm? abstract_id=2381263.

Hollands, F.M.; Tirthali, D., 2014. MOOCs 2014: Expectations and Reality. Full Report. Center for Benefit-Cost Studies of Education, Teachers College, Columbia University, 2014. URL: http://cbcse.org/wordpress/wp-content/uploads/2014/05/

MOOCs_Expectations_and_Reality.pdf

Jordan, K., 2014. Initial Trends in Enrolment and Completion of Massive Open Online Courses. In: International Review of Research in Open and Distance Learning (IRRODL), Vol 15, No 1/2014. URL: http://www.irrodl.org/index.php/irrodl/ article/view/1651/2774

Nesterko, S. O., Seaton, D. T., Kashin, K., Han, Q., Reich, J., Waldo, J., Chuang I., \& Ho, A. D. (2014): World Map of Enrollment (HarvardX Insights). URL: http://harvardx. harvard.edu/harvardx-insights/world-map-enrollment

Shah, D., 2014. MOOCs in 2014: Breaking Down the Numbers, edSurge. URL: https://www.edsurge.com/n/2014-12-26-moocsin-2014-breaking-down-the-numbers

Sloep, P., 2013. MOOCs democratising education? I am not so sure! Technology Enhanced Learning. URL: http://pbsloep. blogspot.de/2013/11/moocs-democratising-education-i-amnot.html

Schulmeister, R., 2014. The Position of xMOOCs in Educational Systems. In: eleed, 10/2014. URL: https://eleed.campussource.de/archive/10/4074

All links cited in the paper are accessed on March 15, 2015. 